\title{
An ectopic thymoma with spontaneous infarction
}

\author{
C. S. Carr, FRCS, and P. A. O'Keefe, FRCS, London, United Kingdom
}

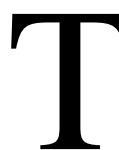

hymomas are uncommon tumors and usually arise within the thymic tissue found in the anterosuperior mediastinum. They are also known to arise in ectopic locations. ${ }^{1-6}$ We present a case in which the benign thymoma underwent infarction within its ectopic location in the right hemithorax inferiorly.

\section{Case History}

A 66-year-old woman, who had previously been well, had sudden onset of severe right-sided chest and neck pain. On physical examination she was pyrexial and had dullness and poor air entry in the right lower part of the thorax. The chest $\mathrm{x}$-ray film suggested a right pleural effusion (Figure 1). This was confirmed by ultrasound, and $500 \mathrm{~mL}$ of hemorrhagic fluid was aspirated. After aspiration of the fluid the chest $\mathrm{x}$-ray film continued to show abnormalities.

Computed tomography showed a large cystic lesion within the right hemithorax (Figure 2). Bronchoscopic examination showed no abnormalities, and further ultrasound-guided aspirations failed to yield additional fluid. She was therefore referred for surgery.

A right thoracotomy was performed. Dense adhesions were present between the lung and chest wall. A cystic mass was adherent to the medial aspect of the middle lobe. This was dissected free and found to have a very narrow pedicle arising from the mediastinal fat. The pedicle was ligated and divided.

She made an uneventful postoperative recovery. Subsequent pathologic examination of the cyst revealed a thin-walled cyst containing blood-stained fluid with a large quantity of yellow caseous material. Microscopic examination showed it to be an infarcted medullary thymoma with the "capsule" composed of dense fibrous tissue with some residual adipose and thymic tissue with foci of calcification (Masaoka stage I).

\section{Discussion}

Thymoma is the most common tumor of the anterior mediastinum, but it can arise in various ectopic locations: the pleural cavity, mimicking mesothelioma"; the pericardium, giving rise to "car-

From the Department Thoracic Surgery, Guy's Hospital, London, United Kingdom.

Received for publication April 30, 2001; accepted for publication May 15, 2001.

Address for reprints: Miss C. S. Carr, Department of Cardiac Surgery, St Thomas' Hospital, Lambeth Palace Rd, London, SE1, United Kingdom (Email: noahalkh@talk21.com).

J Thorac Cardiovasc Surg 2001;122:1234-5

Copyright (C) 2001 by The American Association for Thoracic Surgery

$0022-5223 / 2001 \$ 35.00+0 \quad \mathbf{1 2 / 5 4 / 1 1 7 2 7 5}$

doi:10.1067/mtc.2001.117275

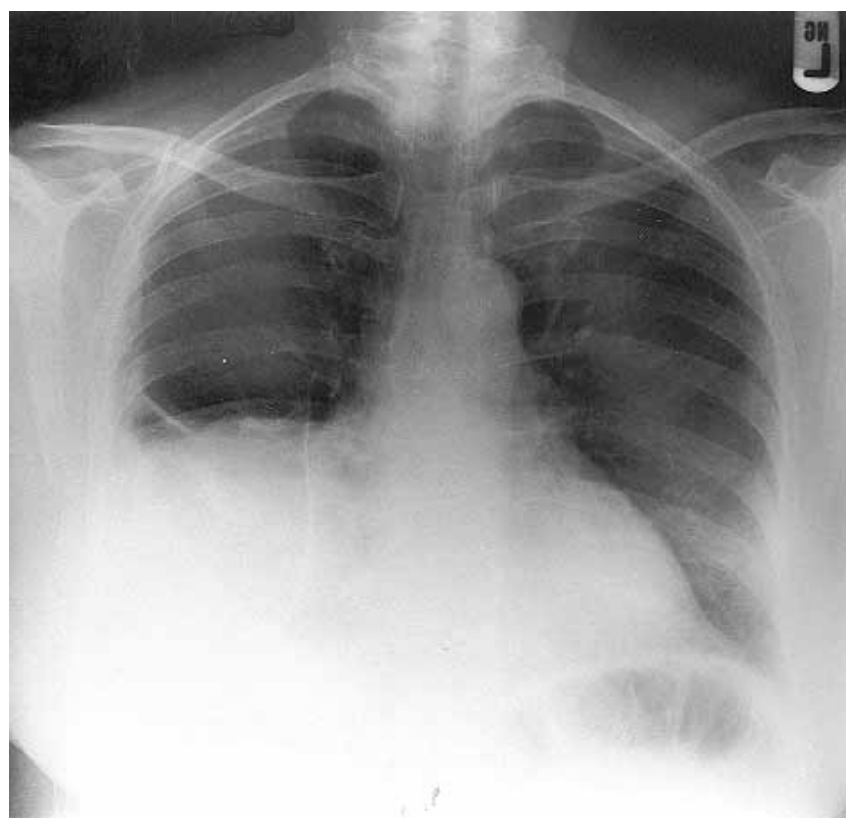

Figure 1. Plain chest $x$-ray film suggesting right pleural effusion.

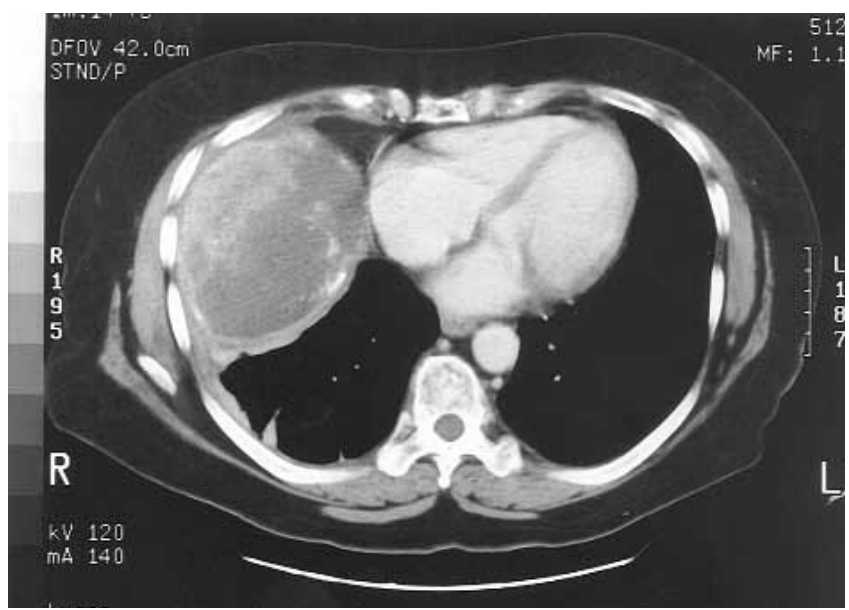

Figure 2. Computed tomographic scan showing a large cystic mass within the right hemithorax.

diomegaly" on chest $\mathrm{x}$-ray films ${ }^{2}$ or associated with pericardial effusion/pericardial tamponade ${ }^{3,4}$; or intrapulmonary ${ }^{5}$ or cervical locations. ${ }^{6}$

Thymomas normally present by their mass effect causing cough, dyspnea, chest pain, or superior vena cava obstruction or via autoim- 
mune/paraneoplastic mechanisms, for example, myasthenia gravis or pure red cell aplasia. Thymomas can also be incidental findings on chest x-ray films or during nuclear cardiac imaging. ${ }^{7}$

Necrosis is death of cells while still part of a living organ/body, whereas infarction is necrosis of tissue because of restricted blood supply, usually as a result of obstruction of the arterial supply by thrombosis or embolism. A polypoid tumor that is supplied by a narrow pedicle may undergo torsion that may lead to infarction, but spontaneous infarction has been reported in parathyroid adenomas,${ }^{8}$ pituitary tumors, ${ }^{9}$ parotid pleomorphic adenoma, ${ }^{10}$ and breast tumors, ${ }^{11}$ none of which is pedunculated. These cases may be related to hemorrhagic infarction or outgrowing of their blood supply.

The case we present is unusual in terms of the ectopic location within the inferior aspect of the right hemithorax and with a presentation suggesting infarction, confirmed on later histologic examination. In our case, it is unlikely that torsion of the pedicle was the cause, because the mass was completely supported by the surrounding tissue. However, the tumor may have outgrown its blood supply, thus precipitating the clinical picture.

\section{References}

1. Fushimi H, Tanio Y, Kotoh K. Ectopic thymoma mimicking diffuse pleural mesothelioma: a case report. Hum Pathol. 1998;29:409-10.
2. Sidhu US, Malhotra V, Chhina GS. An unusual case of pseudocardiomegaly. Chest. 1998;113:1711-4.

3. Ben Hami B, Caulet-Maugendre S, Valla J, Heresbach-Le Berre N, Kernec J, Laurent M, et al. Primary pericardial thymoma: an unusual etiology of neoplastic pericarditis. Ann Pathol. 1996;16:445-8.

4. Lanna TV, Sadaniantz A. Benign thymoma presenting as symptomatic pericardial tamponade. J Am Soc Echocardiogr. 1999;12:679-81.

5. Veynovich B, Masetti P, Kaplan PD, Jasnosz KM, Yousem SA, Landreneau RJ. Primary pulmonary thymoma. Ann Thorac Surg. 1997;64:1471-3.

6. Oh YL, Ko YH, Ree HJ. Aspiration cytology of ectopic cervical thymoma mimicking a thyroid mass: a case report. Acta Cytol. 1998; 42:1167-71.

7. Greyson ND, Freeman M. Incidental detection of a malignant thymic tumor by Tc-99m sestamibi cardiac imaging. Clin Nucl Med. 1998;23:781-2.

8. Otsuka F, Ogura T, Sato T, Hayakawa N, Mimura Y, Kishida M, et al. Hypocalcaemia due to spontaneous infarction of parathyroid adenoma and osteomalacia in a patient with primary hyperparathyroidism. Endocrinol J. 1998;45:617-23.

9. Wichers M, Kristof RA, Springer W, Schramm J, Klingmuller D. Pituitary apoplexy with spontaneous cure of acromegaly and its possible relation to Gd-DTPA-administration. Acta Neurochir (Wien). 1997;139:992-4.

10. Layfield LJ, Reznicek M, Lowe M, Bottles K. Spontaneous infarction of a parotid gland pleomorphic adenoma: report of a case with cytologic and radiographic overlap with a primary salivary gland malignancy. Acta Cytol. 1992;36:381-6.

11. Matias-Guiu X, Calabuig R, Badia F, Serra J, Sa Calle JP. Spontaneous infarcts in fibroadenomas of the breast. Curr Surg. 1988;45:277-9. 